\title{
An investigation on cardioprotective potential of Marrubium vulgare aqueous fraction against ischaemia-reperfusion injury in isolated rat heart
}

\author{
A. Garjani' ${ }^{1}$ D. Tila1 ${ }^{1}$, S. Hamedeyazdan ${ }^{3}$, H. Vaez ${ }^{1}$, M. Rameshrad ${ }^{1}$, M. Pashaii ${ }^{2}$, F. Fathiazad ${ }^{3}$ \\ ${ }^{1}$ Department of Pharmacology and Toxicology, School of Pharmacy, Tabriz University of Medical Sciences, Tabriz, Iran \\ 2Student Research Committee, School of Pharmacy, Tabriz University of Medical Sciences, Tabriz, Iran \\ ${ }^{3}$ Department of Pharmacognosy, School of Pharmacy, Tabriz University of Medical Sciences, Tabriz, Iran
}

[Received: 27 August 2016; Accepted: 27 December 2016]

Background: The aim of this study was to evaluate the cardioprotective effects of aqueous fraction of Marrubium vulgare hydroalcoholic extract on cardiac parameters in ischaemic-reperfused isolated rat hearts.

Materials and methods: The aerial parts of the plant were extracted with methanol $70 \%$ by maceration. The water-soluble portion of the total hydroalcoholic extract was prepared with liquid-liquid extraction (LLE). Afterwards, the antioxidant activity, total phenolic and flavonoids content of the aqueous fraction were determined. In order to evaluate the effects of the aqueous fraction on cardiac parameters and ischaemia-reperfusion (I/R) injury, the Langendroff method was used on male Wistar rats. Harvested hearts were cannulated immediately to the Langendroff apparatus and subjected into 30 min regional ischaemia and $2 \mathrm{~h}$ reperfusion, either by a modified Krebs-Henseleit buffer (KHB) solution or enriched KHB solution with plant extract $(10,20,40 \mu \mathrm{g} / \mathrm{mL})$.

Results: The aqueous fraction was found to be a scavenger of DPPH radical with RC50 value of $47 \mu \mathrm{g} / \mathrm{mL}$. The total phenolic and flavonoids content of the fraction was $6.05 \mathrm{~g}$ gallic acid equivalent and $36.13 \mathrm{mg}$ quercetin equivalent per $100 \mathrm{~g}$ of dry plant material. In addition, $40 \mathrm{\mu g} / \mathrm{mL}$ of Marrubium vulgare aqueous fraction significantly decreased infarct size in comparison to control group. All doses considerably reduced the total ventricular ectopic beats during 30 min of ischaemia. The extract at dose of $40 \mu \mathrm{g} / \mathrm{mL}$ noticeably decreased the arrhythmias during the first 30 min of reperfusion.

Conclusions: The results of the study indicated aqueous fraction of Marrubium vulgare possesses a protective effect against I/R injuries in isolated rat hearts. (Folia Morphol 2017; 76, 3: 361-371)

Key words: Marrubium vulgare, ischaemia-reperfusion (I/R) injury, Langendroff, ventricular ectopic beats, arrhythmias

\section{INTRODUCTION}

Ischaemia-reperfusion (I/R) injury is one of the important life-threaten medical problems worldwide. In recent years, various experiments and clinical studies have been conducted to introduce effective natural compounds which can improve the function of the affected tissues or decrease the detrimental consequences of $\mathrm{I} / \mathrm{R}$ injury $[18,29]$. In ischaemia by

Address for correspondence: Prof. F. Fathiazad, Department of Pharmacognosy, Tabriz University of Medical Sciences, Tabriz, Iran, tel: +984133372253, fax: +98413334798, e-mail: fathiazad@yahoo.com; fathiazad@tbzmed.ac.ir 
circulatory arrest, the aerobic metabolism turns into anaerobic due to the imbalance between oxygen demand and supply. The anaerobic metabolism leads to the reduction of intracellular $\mathrm{pH}$ which results in ionic homeostasis disturbances. Although a welltimed reperfusion is fundamental for recovery of a dying myocardium but by sudden restoration of blood flow to the ischaemic myocardium, a burst of reactive oxygen species (ROS) will be produced as a reaction to hyperoxia which can make the situation worse. This phenomenon is known as myocardial I/R injury [1].

The overproduction of ROS not only influences the process of injury directly but also exacerbates the circumstance indirectly. ROS can initiate the oxidation of lipids in cell membrane, oxidation of proteins and cause DNA fragmentation (directly) whereas these species can intensify the ionic derangement i.e. $\mathrm{Ca}^{2+}$ overload in cytosol and induce the inflammatory factors (indirectly). As a result, the myocytes death occurs and myocardium loses its ability to function well $[6,26]$.

Marrubium vulgare L., known as horehound, is a medicinal herb from Lamiaceae family which mainly grows in North Africa, Central and Western Asia and also in some parts of Europe [19]. This perennial plant is widely distributed in northern and eastern provinces of Iran [10, 27]. M. vulgare is a popular medicinal herb and in traditional medicine has been used as a neurosedative, hypotensive, antispasmodic, antinociceptive, antidiabetic and anti-inflammatory agent. Studies dealing with the biological activities on the plants of Marrubium genus, revealed anticoagulant, anti-inflammatory, immunomodulating, cytotoxicity, vasorelaxant, hepatoprotective, hypolipidaemic, hypoglycaemic and antioxidant properties $[4,5]$. The merit of the traditional use of $M$. vulgare along with its reported biological activities have been supported by the isolation and identification of a group of biologically active phytochemicals such as diterpenes, flavonoids, phenylpropanoid esters, tannins and sterols. Detailed phytochemical screening of $M$. vulgare showed that the plant is rich in marrubiin diterpene, flavonoid compounds such as luteolin, apigenin, quercetin, isoquercitrin, chrysoeriol, vitexin and polyphenols such as proanthocyanidins (Condensed tannins) [2, 20, 21, 24, 25]. Phenylpropanoids, a group of phenolics, were mostly detected in $M$. vulgare including acteoside, forsythoside $B$, arenarioside, ballotetroside, marruboside, and acethyl marruboside. Among them, acteoside, also known verbascoside, is the principle phenylpropanoid that is believed to be one of the key bioactive compound and responsible for many health benefits of the plant. Proanthocyanidins, the water-soluble subclass of the phenolic group, are composed of flavanol (catechins) units and rich in green tea, red wine, grape seeds and fruits like blueberries, strawberries, red apple and in nuts such as hazelnut and pistachio [1, 12, 22]. Catechin and epicatechin are the two most studied compounds from proanthocyanidins. Many studies have been done in order to prove that catechins play an important role in cure of myocardial ischaemia and reduce the mortality risk of cancer, myoglobinuric acute renal failure and congestive heart failure due to antioxidant, anti-inflammatory, and vasodilatory effects $[12,16]$. These components give the plant superior antioxidant content. Hence, $M$. vulgare has potential in promotion of health and prevention of conditions associated with inflammation, cardiovascular disease, dyslipidaemia, cancer, hyperglycaemia or increased oxidative stress. In this paper, concerning the polyephenols role in scavenging free radicals and with inspiration from Yousefi et al. [27] study which showed the cardioprotective effect of methanoilc extract of $M$. vulgare, it has been decided to evaluate whether the aqueous extract of $M$. vulgare has the cardioprotective effect against myocardial I/R injury.

\section{MATERIALS AND METHODS}

\section{Solvents and chemicals}

Methanol, ethyl acetate, chloroform, petroleum ether and the Krebs-Henseleit buffer (KHB) solution ingredients (potassium dihydrogen phosphate, potassium chloride, magnesium chloride, sodium chloride, D-glucose, calcium chloride and sodium bicarbonate) all from Merck company (Germany) were used. Ketamine and xylazine were from Alfasan, Netherlands. Evans blue from Sigma, Japan and the triphenyl tetrazolium chloride (TTC) from Baker (England) were used. 2,2-diphenyl-1-picrylhydrazyl (DPPH), Folin-Ciocalteu reagent and aluminium chloride all from Sigma Aldrich chemical company (USA) were used. All other reagents and chemicals were of analytical grade.

\section{Animals}

Healthy male albino Wistar rats (270-300 g) were used in this study. They were housed in the standard cages, under a $12 \mathrm{~h}$ light/dark cycle. The animals were given food and water freely. The present study was done regarding the Guide for the Care and Use 
of Laboratory Animals of Tabriz University of Medical Sciences, Tabriz, Iran.

\section{Extract preparation}

The aerial parts of $M$. vulgare were collected during flowering stage from Kiasar, Mazandaran province, Iran. The air-dried plant materials (500 g) were grounded and powdered finely and then defatted by petroleum ether $(2 \mathrm{~L} \times 2)$ at $25^{\circ} \mathrm{C}$. Afterwards, the plant materials were extracted with methanol $70 \%$ by maceration $(2 \mathrm{~L} \times 4)$ at room temperature and the solvent was removed at $40^{\circ} \mathrm{C}$ using rotary evaporator. Subsequently, the water-soluble portion of the total hydroalcoholic extract was prepared after removing the non-polar fractions through liquid-liquid extraction (LLE) with chloroform and ethyl acetate, respectively. The water of resultant aqueous extract containing polar compounds was dried under reduced pressure, and the dried extract was kept in the refrigerator until the phytochemical analyses and pharmacological procedure.

\section{DPPH radical scavenging assay}

This assay was performed using the method proposed by Hamedeyazdan et al. [10]. 2, 2-diphenyl-1-picrylhydrazyl, known as DPPH, is a reagent which is used in laboratory assays in order to determine the antioxidant capacity of different samples, especially the herbal extracts. It composes of free radical molecules that make the colour of a solution purple and by neutralisation the colour turns into pale yellow. The stock concentration $1000 \mu \mathrm{g} / \mathrm{mL}$ of the aqueous fraction of the $M$. vulgare extract was prepared and then diluted with methanol to the concentrations below: 500, 250, 125, 62.5, 31.25 and $15.62 \mu \mathrm{g} / \mathrm{mL}$.

All these concentrations were prepared in the volume of $2 \mathrm{~mL}$. The same volume $(2 \mathrm{~mL})$ of $0.004 \%$ of DPPH solution was added to each tube. After $30 \mathrm{~min}$ incubation in $25^{\circ} \mathrm{C}$, the absorbance was read against blank at $517 \mathrm{~nm}$. Tests were carried out in triplicate where the average absorption was reported for each concentration. This test was done with quercetin as the positive control. The free radical scavenging of the extract was calculated in percent by the equation below:

$$
\mathrm{R} \%=\left[\left(\mathrm{A}_{\text {blank }}-\mathrm{A}_{\text {sample }}\right) / \mathrm{A}_{\text {blank }}\right] \times 100
$$

where $A_{b l a n k}$ is the absorbance of the solvent (containing all reagents except the plant extract) and $A_{\text {sample }}$ is the absorbance of the sample. RC50 is the concen- tration of the plant extract reducing $50 \%$ of the free radicals which was calculated from the graph of $\mathrm{R} \%$ against aqueous extract concentrations in $\mu \mathrm{g} / \mathrm{mL}$.

\section{Total phenolic content assay}

This assay was done through Folin-Ciocalteau method in order to determine the total phenol values [10]. $0.5 \mathrm{~mL}$ of aqueous fraction of $M$. vulgare solution were mixed with $5 \mathrm{~mL}$ Folin-Ciocalteau reagent (diluted in distilled water 1:10). After $5 \mathrm{~min}, 4 \mathrm{~mL}$ of $\mathrm{Na}_{2} \mathrm{CO}_{3} 1 \mathrm{M}$ was added to the mixture and shaken well. Following the incubation of the mixture at room temperature for about $15 \mathrm{~min}$, the absorbance was measured by UV-VIS spectrophotometer at $765 \mathrm{~nm}$. The standard curve was prepared by $50-250 \mu \mathrm{g} / \mathrm{mL}$ solutions of gallic acid in methanol: water (50:50) against the absorbance. The total phenolic content of the aqueous fraction was expressed as gallic acid equivalents, in $\mathrm{mg} / 100 \mathrm{~g}$ of dry plant material.

\section{Total flavonoids content assay}

In order to determine the total flavonoids content in $M$. vulgare aqueous fraction, the colorimetric aluminium chloride method was performed [10]. $0.5 \mathrm{~mL}$ of the aqueous fraction with $1.5 \mathrm{~mL}$ methanol, $0.1 \mathrm{~mL} \mathrm{AlCl} 310 \%, 0.1 \mathrm{~mL}$ potassium acetate $1 \mathrm{M}$ and $2.8 \mathrm{~mL}$ distilled water were mixed and shaken well. The mixture was allowed to stand at room temperature for $30 \mathrm{~min}$, later the absorbance of the mixture was measured by UV-VIS spectrophotometer at $415 \mathrm{~nm}$.

The calibration curve was drawn by $31.25-250$ $\mu \mathrm{g} / \mathrm{mL}$ of quercetin solutions in methanol. The value of total flavonoids was reported in $\mathrm{mg}$ per $100 \mathrm{~g}$ of dry plant material which was equivalent to quercetin.

\section{Nitric oxide radical inhibition assay}

This assay was done according to Griess Illosvoy reaction. The reaction mixtures $(3 \mathrm{~mL})$ containing sodium nitroprusside (10 mM, $2 \mathrm{~mL}$ ), phosphate buffer $(\mathrm{pH}: 7.4,0.5 \mathrm{~mL})$ and different concentrations of $M$. vulgare aqueous fraction $(0.5 \mathrm{~mL})$ were incubated at room temperature for $150 \mathrm{~min}$, then $1 \mathrm{~mL}$ of sulphanilic acid reagent $(0.33 \%$ in glacial acetic acid $20 \%$ ) was added to $0.5 \mathrm{~mL}$ of each reaction mixture. After being left for $5 \mathrm{~min}, 1 \mathrm{~mL}$ of naphthyl ethylene diamine dihydrochloride as a Griess reagent was added and they were allowed to stand for $30 \mathrm{~min}$ at $25^{\circ} \mathrm{C}$. Afterward, absorbances of the mixtures were 
measured by UV-VIS spectrophotometer at $540 \mathrm{~nm}$. Quercetin was used as the positive control [23]. The nitric oxide radical scavenging of the aqueous fraction was calculated in percent by the equation below:

$$
R \%=\left[\left(A_{\text {blank }}-A_{\text {sample }}\right) / A_{\text {blank }}\right] \times 100
$$

where $A_{\text {blank }}$ is the absorbance of the solvent (containing all reagents except the plant extract), $A_{\text {sample }}$ is the absorbance of the sample and $\mathrm{R} \%$ represents the reduction percent. RC50 is the concentration of the plant extract reducing $50 \%$ of nitric oxide radicals which was calculated from the graph of $\mathrm{R} \%$ against different concentrations of $M$. vulgare aqueous extract in $\mu \mathrm{g} / \mathrm{mL}$.

\section{TLC analysis}

To determine the presence of acteoside, the main phenylpropanoid, and bioactive compound in M. vulgare aqueous extract, the extract was subjected to qualitative thin layer chromatography (TLC) using pure acteoside as standard, solvent system chloroform: methanol: water (60:40:8) and stationary phase silicagel GF254 (Merck). The spot of acteoside was visualised by irradiation the TLC plate with ultraviolet light and spraying Alcl3 5\% reagent.

\section{Qualitative Stiasny assay}

The aqueous extract $(10 \mathrm{~mL})$ was mixed with mixture of hydrochloric acid and formaldehyde (1:2, $5 \mathrm{~mL}$ ) and allowed to be heated under reflux for $30 \mathrm{~min}$. The red-brown precipitation is a sign of catechins presence [8].

\section{The pharmacological procedure}

Male Wistar rats (270-300 g) were subjected into four groups $(n=6)$. Group number one is the control group that was perfused by KHB solution. The second, the third and the fourth groups were received KHB solution with different concentrations of aqueous fraction (10, 20 and $40 \mu \mathrm{g} / \mathrm{mL}$, respectively) $5 \mathrm{~min}$ before ischaemia induction.

The rats were heparinised and anesthetised with the mixture of ketamine and xylazine. From the moment that the hearts were cannulated to the constantpressure Langendorff system (within the KHB solution circulation which was oxygenated by $95 \% \mathrm{O}_{2} / 5 \% \mathrm{CO}_{2}$ and with the $80 \mathrm{~mm} \mathrm{Hg}$ pressure and the temperature of $37^{\circ} \mathrm{C}$ ) until the ischaemia induction time, was a period of 20 min which is called stabilisation phase. During this period, the hearts which were not follow- ing a stable steady-state pattern were rejected. In the treated groups, 5 min before the end of the stabilisation phase, the hearts were perfused by $M$. vulgare aqueous fraction until the end of the reperfusion phase. Ischaemic phase started right after the stabilisation period. It was induced by occluding of left anterior descending coronary artery (LAD) via two plastic pipette tips which is known as regional ischaemia and lasted for $30 \mathrm{~min}$. By removing these plastic tips after $30 \mathrm{~min}$ of ischaemia, the reperfusion phase began. This phase continued for $120 \mathrm{~min}$ and after that the suture around the LAD was tied (knot) and then the hearts were ready for Evans blue staining which was perfused via the aortic cannula [3].

\section{Hemodynamic changes record}

After mounting the heart on the Langendorff apparatus, a latex balloon connected to pressure transducer was inserted into the left ventricle in order to measure the left ventricular systolic and diastolic pressure (LVSP and LVDP, respectively), develop pressure (DP) and heart rate $(H R)[3,23]$. Left ventricular developed pressure $=$ LVSP - LVDP. The output volumes of KHB solution from the hearts were measured at special time intervals (flow rate):

- end of stabilisation phase;

$-5,10,15,20,25$ and 30 min of ischaemia phase;

- 5, 10, 15, 20, 25, 30, 45, 60, 90 and $120 \mathrm{~min}$ of reperfusion phase.

\section{Lactate levels measurement}

The perfused KHB solutions from the hearts were collected in microtubes at the end of stabilisation period, $30 \mathrm{~min}$ of ischaemia phase and the first $30 \mathrm{~min}$ of reperfusion period. The lactate levels of these samples (the marker of the anaerobic glycolysis) were measured with lab assays $[15,20]$.

\section{Infarct size and staining protocol}

In regional ischaemia double staining strategy (Evans blue and TTC, respectively) is performed.

After tying secure knots and occluding LAD coronary arteries, the hearts were separated from the Langendorff apparatus and Evans blue $0.25 \%$ in saline) was infused into the hearts via cannula. The non-risk zone areas became dark blue and the risk zone areas stayed pale pink. Following the freezing of the hearts, TTC staining was applied which the viable myocytes absorbed the dye and became brickred but the non-viable myocardium cells got the pale 

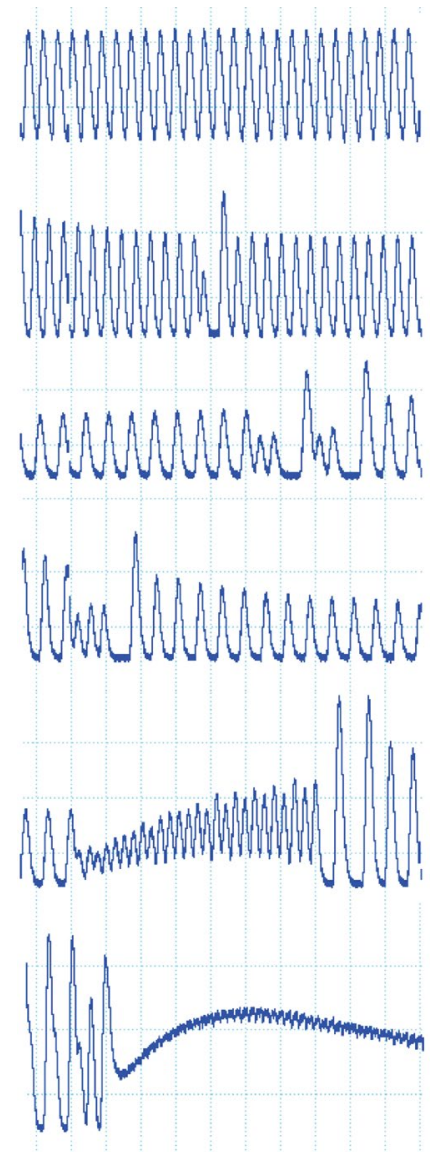

Figure 1. Arrhythmia's rhythm. From the top to the bottom: normal rhythm, Single ectopic beat, salvos ectopic beats, triplet ectopic beat, ventricular tachycardia and ventricular fibrillation.

appearances [3]. The risk zone areas and infarct sizes were measured by equations below:

- Risk zone area (\%) = (non-perfused area) / (total area of the heart) $\times 100$;

- Infarct size $(\%)=($ dead cells area $) /$ (non-perfused area) $\times 100$.

\section{Enumeration of arrhythmias}

By a latex balloon connected to pressure transducer in the left ventricle, the normal rhythm of the hearts and the irregular heartbeats (single, salvo, triplet, ventricular tachycardia [VT] and ventricular fibrillation [VF]) were recorded. The arrhythmias were studied by the Lambeth Law. The irregular heartbeats are shown in Figure 1.

\section{Statistical analysis}

The results of infarct sizes, haemodynamic parameters and lactate concentrations in different groups were analysed by one-way ANOVA and presented as mean \pm standard error of the mean (SEM). The results of total ventricular ectopic beats (VEBs) which is the sum of (single, salvo, triplet and VT) and the duration of VT and reversible VF in ischaemia and the first 30 min of reperfusion phase were analysed by non-parametric Mann-Whitney U-test and expressed in mean \pm SEM in different groups.

For statistical comparison, the incidence of VT and VF results in different groups are analysed by Fisher's exact test and expressed in percent.

The analysis of all data was done by SPSS Statistics 17.0 software.

\section{RESULTS}

\section{DPPH radical scavenging assay}

The radical scavenging activity of aqueous fraction of $M$. vulgare extract was determined by DPPH assay. According to the results, the RC50 value for aqueous fraction and quercetin were determined as $47 \mu \mathrm{g} / \mathrm{mL}$ and $3.2 \mu \mathrm{g} / \mathrm{mL}$, respectively.

\section{Total phenolic content assay}

The total phenolic content was determined from the standard curve via the equation below:

- Absorbance $=0.0063 \times$ gallic acid $(\mu \mathrm{g})+0.0372$, $\left(R^{2}=0.999\right)$;

- The total phenolic content of the plant aqueous extract was equivalent to $6.05 \mathrm{~g}$ of gallic acid per $100 \mathrm{~g}$ dry plant material.

\section{Total flavonoids content assay}

The assay was done by colorimetric aluminium chloride method and the absorbance of the plant extract was calculated from the equation of the standard curve which is shown below:

- Absorbance $=0.0088 \times$ quercetin $(\mu \mathrm{g})-0.0625$, $\left(R^{2}=0.9965\right)$;

- The total flavonoids content of the plant aqueous extract was equivalent to $36.13 \mathrm{mg}$ of quercetin per $100 \mathrm{~g}$ dry plant material.

\section{Nitric oxide radical inhibition assay}

According to the obtained data, no inhibitory activity for nitric oxide radicals by $M$. vulgare aqueous fraction was detected.

\section{TLC analysis}

Following the TLC of the extract the $R_{f}$ value of acteoside was calculated as 0.62 which was consistent with $R_{f}$ of standard acteoside. 
Table 1. Effects of Marrubium vulgare aqueous fraction (10, 20 and $40 \mu \mathrm{g} / \mathrm{mL})$ on ischaemia-reperfusion (I/R)-induced cardiac arrhythmias during 30 of min ischaemic phase

\begin{tabular}{|c|c|c|c|c|c|c|c|c|c|}
\hline \multirow{2}{*}{$\begin{array}{l}\text { Ischaemic } \\
\text { phase }\end{array}$} & \multicolumn{5}{|c|}{ Number } & \multicolumn{2}{|c|}{ Duration [s] } & \multicolumn{2}{|c|}{ Incidence [\%] } \\
\hline & Single & Salvo & Triplet & VT & VEBs & VT & VF & VT & VF \\
\hline Control & $458.3 \pm 26.9$ & $77.5 \pm 11.9$ & $25.3 \pm 5.3$ & $398.3 \pm 141.7$ & $959.3 \pm 161$ & $56.6 \pm 21.9$ & 5.3 & 100 & 25 \\
\hline $\begin{array}{l}\text { M. vulgare ext. } \\
10 \mu \mathrm{g} / \mathrm{mL}\end{array}$ & $231 \pm 7.6^{*}$ & $14.8 \pm 3.7^{*}$ & $2.4 \pm 1.1^{*}$ & $125.3 \pm 19.4$ & $350.2 \pm 25.8^{*}$ & $24.5 \pm 4$ & 0 & 100 & 0 \\
\hline $\begin{array}{l}\text { M. vulgare ext. } \\
20 \mu \mathrm{g} / \mathrm{mL}\end{array}$ & $83.7 \pm 6.4^{*}$ & $7.3 \pm 1.9^{*}$ & $2.5 \pm 0.8^{*}$ & $46.5 \pm 11^{*}$ & $140 \pm 8.8^{*}$ & $9 \pm 2.2^{*}$ & 0 & 100 & 0 \\
\hline $\begin{array}{l}\text { M. vulgare ext. } \\
40 \mu \mathrm{g} / \mathrm{mL}\end{array}$ & $79.5 \pm 9.1^{*}$ & $7 \pm 2.1^{*}$ & $3.3 \pm 1.3^{*}$ & $53.3 \pm 4.5^{*}$ & $143 \pm 14.1^{*}$ & $9.9 \pm 0.9^{*}$ & 0 & 100 & 0 \\
\hline
\end{tabular}

${ }^{*} \mathrm{p}<0.05$ vs. the control group; $\mathrm{n}=6$ in each group; VEBs - ventricular ectopic beats (single + salvo + triplet + VT); VT — ventricular tachycardia; VF - ventricular fibrillation

Table 2. Effects of Marrubium vulgare aqueous fraction (10, 20 and $40 \mu \mathrm{g} / \mathrm{mL})$ on ischaemia-reperfusion (l/R)-induced cardiac arrhythmias during the first 30 min of reperfusion phase

\begin{tabular}{|c|c|c|c|c|c|c|c|c|c|}
\hline \multirow{2}{*}{$\begin{array}{l}\text { Ischaemic } \\
\text { phase }\end{array}$} & \multicolumn{5}{|c|}{ Number } & \multicolumn{2}{|c|}{ Duration [s] } & \multicolumn{2}{|c|}{ Incidence [\%] } \\
\hline & Single & Salvo & Triplet & VT & VEBs & VT & VF & VT & VF \\
\hline Control & $64 \pm 9.7$ & $6.2 \pm 1.4$ & $0.6 \pm 0.4$ & $2 \pm 2$ & $72.8 \pm 10.4$ & $0.4 \pm 0.4$ & $5 \pm 5$ & 0 & 25 \\
\hline $\begin{array}{l}\text { M. vulgare ext. } \\
10 \mu \mathrm{g} / \mathrm{mL}\end{array}$ & $37.6 \pm 10.1$ & $1.4 \pm 0.7^{*}$ & $0.4 \pm 0.4$ & 0 & $39.2 \pm 9.9$ & 0 & 0 & 0 & 0 \\
\hline $\begin{array}{l}\text { M. vulgare ext. } \\
20 \mu \mathrm{g} / \mathrm{mL}\end{array}$ & $47.4 \pm 7.5$ & $1.6 \pm 1.2^{*}$ & $0.4 \pm 0.2$ & $2 \pm 2$ & $51.4 \pm 8.9$ & $0.3 \pm 0.3$ & 0 & 20 & 0 \\
\hline $\begin{array}{l}\text { M. vulgare ext. } \\
40 \mu \mathrm{g} / \mathrm{mL}\end{array}$ & $36.7 \pm 4.8^{*}$ & $2.5 \pm 0.5^{*}$ & $0.3 \pm 0.3$ & 0 & $39.5 \pm 4.8^{*}$ & 0 & 0 & 0 & 0 \\
\hline
\end{tabular}

${ }^{*} \mathrm{p}<0.05$ vs. the control group; $\mathrm{n}=6$ in each group; VEBs - ventricular ectopic beats (single + salvo + triplet + VT); VT - ventricular tachycardia; VF — ventricular fibrillation

Table 3. The effects of Marrubium vulgare aqueous extract $(10,20$ and $40 \mu \mathrm{g} / \mathrm{mL})$ on the ischaemia-reperfusion (l/R)-induced infarct size in isolated rat hearts

\begin{tabular}{lcccc}
\hline & Control & $\begin{array}{c}\text { M. vulgare } \\
\text { extract } 10 \mu \mathrm{g} / \mathrm{mL}\end{array}$ & $\begin{array}{c}\text { M. vulgare } \\
\text { extract } 20 \mu \mathrm{g} / \mathrm{mL}\end{array}$ & $\begin{array}{c}\text { M. vulgare } \\
\text { extract } 40 \mu \mathrm{g} / \mathrm{mL}\end{array}$ \\
\hline Infarct size $(\%)$ & $50.58 \pm 1.23$ & $54.21 \pm 5.81$ & $44.57 \pm 3.23$ & $15.61 \pm 1.29^{* * *}$ \\
\hline
\end{tabular}

${ }^{* *} p<0.001$ vs. the control group; $n=6$ in each group

\section{Qualitative Stiasny assay}

Following this assay, a brick-red colour precipitation revealed the presence of catechins in the aqueous fraction of $M$. vulgare hydroalcoholic extract.

The effects of aqueous extract of $M$. vulgare on the ischaemic and the first $\mathbf{3 0} \mathrm{min}$ of reperfusion phase arrhythmias

The effects of aqueous extract of $M$. vulgare on the ischaemic and the first $30 \mathrm{~min}$ of reperfusion phase arrhythmias are shown in Table 1.

As shown in Table 1, the aqueous extract significantly decreased the total VEBs during ischaemic phase at all three doses $(10,20$ and $40 \mu \mathrm{g} / \mathrm{mL})$ and also considerably reduced the VT duration at the doses of $20 \mu \mathrm{g} / \mathrm{mL}$ and $40 \mu \mathrm{g} / \mathrm{mL}$. No VF was shown in the ischaemic period in treated groups.

The effects of the extract on arrhythmias that appeared during the first $30 \mathrm{~min}$ of reperfusion phase are shown in Table 2.

According to the table, the extract decreased the total VEBs with $40 \mu \mathrm{g} / \mathrm{mL}$ significantly. Although the doses of $10 \mu \mathrm{g} / \mathrm{mL}$ and $20 \mu \mathrm{g} / \mathrm{mL}$ decreased the total VEBs but the effects were not significant. No VT was seen in reperfusion phase in the groups which treated by $10 \mu \mathrm{g} / \mathrm{mL}$ and $40 \mu \mathrm{g} / \mathrm{mL}$ and there was also no occurrence of $\mathrm{VF}$ in all three treated groups. 


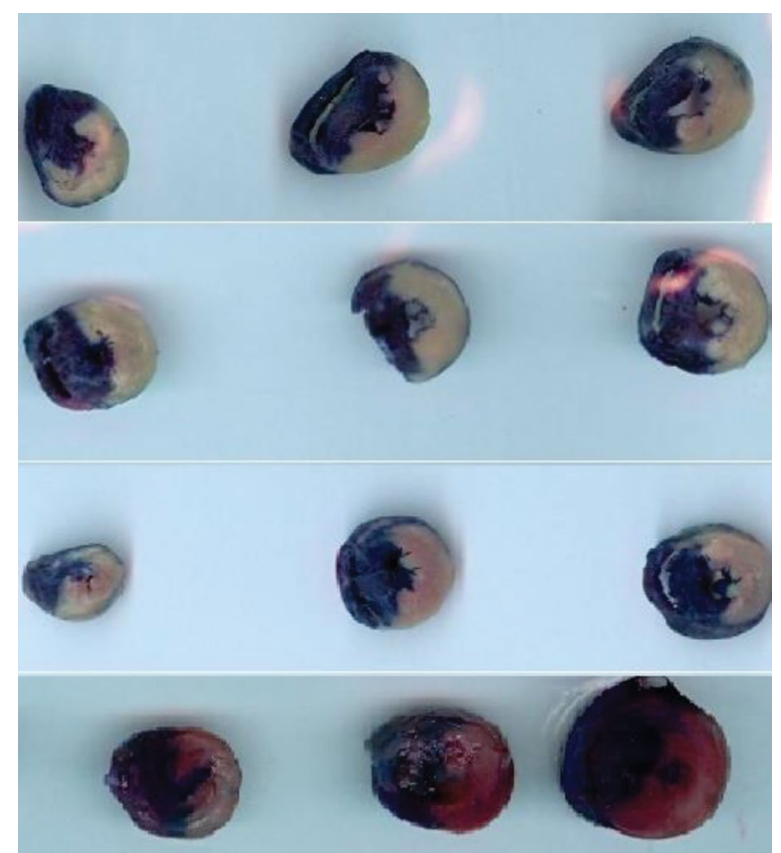

Figure 2. The samples of sliced hearts after double staining. From the top to the bottom: Control group, ext. $10 \mu \mathrm{g} / \mathrm{mL}$, ext. $20 \mu \mathrm{g} / \mathrm{mL}$ and ext. $40 \mu \mathrm{g} / \mathrm{mL}$ of Marrubium vulgare aqueous extract. Non-risk zone areas are dark blue. Viable myocytes are brick-red. Non-viable myocardium cells are pale.

\section{The effect of aqueous extract of $M$. vulgare on infarct size}

Regarding Table 3 and Figure 2, the $M$. vulgare aqueous extract decreased infarct size at the doses of $20 \mu \mathrm{g} / \mathrm{mL}$ and $40 \mu \mathrm{g} / \mathrm{mL}$. The reduction with dose of $40 \mu \mathrm{g} / \mathrm{mL}$ was striking and significant $\left({ }^{* *} p<0.001\right)$.

\section{The effect of aqueous extract of $M$. vulgare} on flow rate parameter during $\mathbf{l} / \mathbf{R}$

Figure 3 is representing the result of flow rate during the whole period of experiment. By ligation of coronary artery at the end of stabilisation phase, the flow rate decreased from $100 \%$ to $70 \pm 0.05 \%$ during 30 min of ischaemia in control group. By reperfusion, the flow rate elevated again to $86 \pm 0.06 \%$ and then gradually decreased to $37 \pm 0.05 \%$ during $120 \mathrm{~min}$ of reperfusion phase. The extract at all three doses (especially $40 \mu \mathrm{g} / \mathrm{mL}$ ) caused a great decline in flow rate in $30 \mathrm{~min}$ of ischaemia as compared to control group. In $120 \mathrm{~min}$ of reperfusion period, the flow rates in all treated groups were higher than control group, but no significant changes were occurred.

The considerable changes of flow rate in control and treated groups are shown in Figure 3 by $p$ values $\left({ }^{* *} p<0.01,{ }^{*} p<0.05\right)$.

\section{The effect of aqueous extract of $M$. vulgare on heart rate parameter during $\mathbf{I} R$}

Figure 4 is showing the result of HR during the whole period of experiment. By the ischaemia induction, the HR decreased from $97 \pm 0.01 \%$ to $76 \pm 0.06 \%$ in control group. By reperfusion, the HR increased up to $84 \pm 0.05 \%$ and gradually decreased to $67 \pm 0.04 \%$ during $120 \mathrm{~min}$ of reperfusion phase. Among all three doses of aqueous extract of $M$. vulgare, only the dose of $40 \mu \mathrm{g} / \mathrm{mL}$ decreased the HR during the both ischaemia and the reperfusion phases as compared to control group. Hence the aqueous extract induced bradycardia but not significantly.

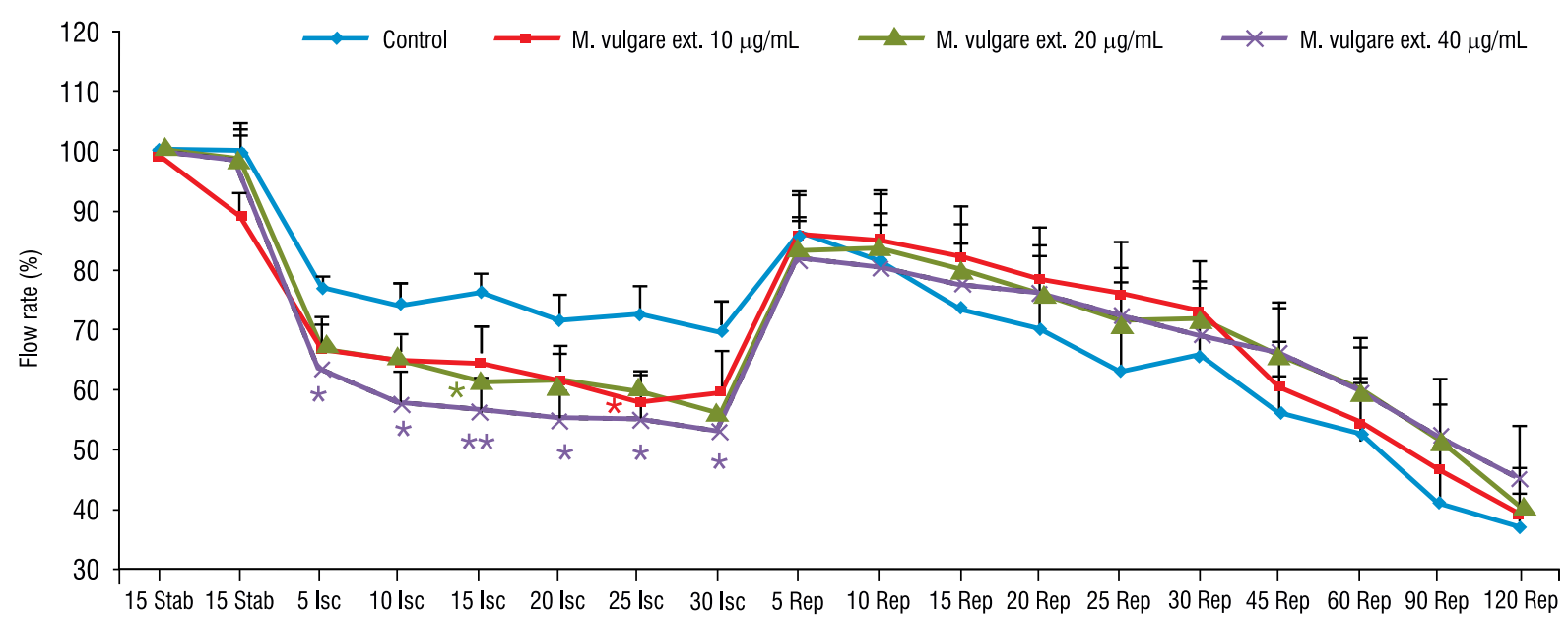

Figure 3. Flow rate in the control and treated groups receiving 10, 20 and $40 \mu \mathrm{g} / \mathrm{mL}$ of Marrubium vulgare aqueous fraction during whole experiment period. Data are normalised to $15 \mathrm{Stab}$ and represented as mean \pm standard error of the mean (SEM); Stab - stabilisation; Isc — ischaemia; Rep — reperfusion; Ext — extract; $n=6$ rats in each group; ${ }^{*} p<0.01,{ }^{*} p<0.05$. 


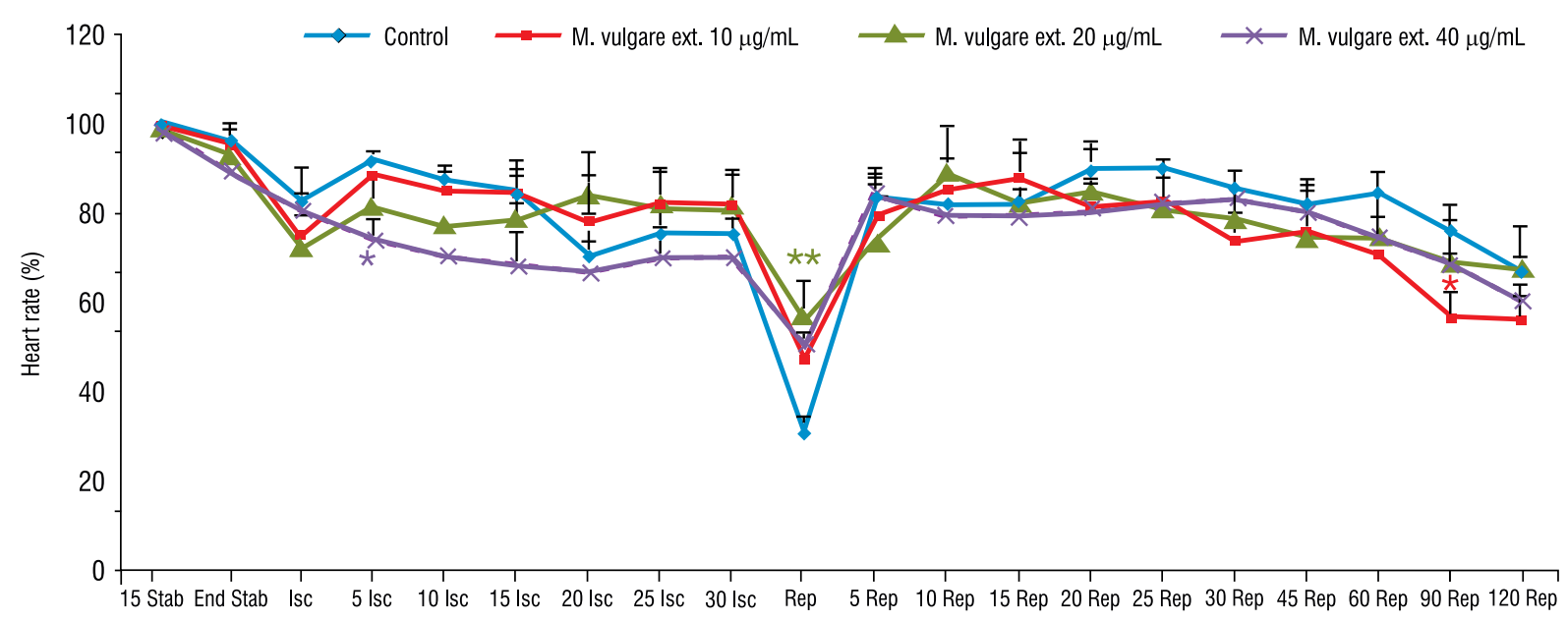

Figure 4. Heart rate in the control and treated groups receiving 10, 20 and $40 \mu \mathrm{g} / \mathrm{mL}$ of Marrubium vulgare aqueous fraction during whole experiment period. Data are normalised to $15 \mathrm{Stab}$ and represented as mean \pm standard error of the mean (SEM); Stab - stabilisation; Isc — ischaemia; Rep — reperfusion; Ext - extract; $n=6$ rats in each group; ${ }^{* *} p<0.01,{ }^{*} p<0.05$.

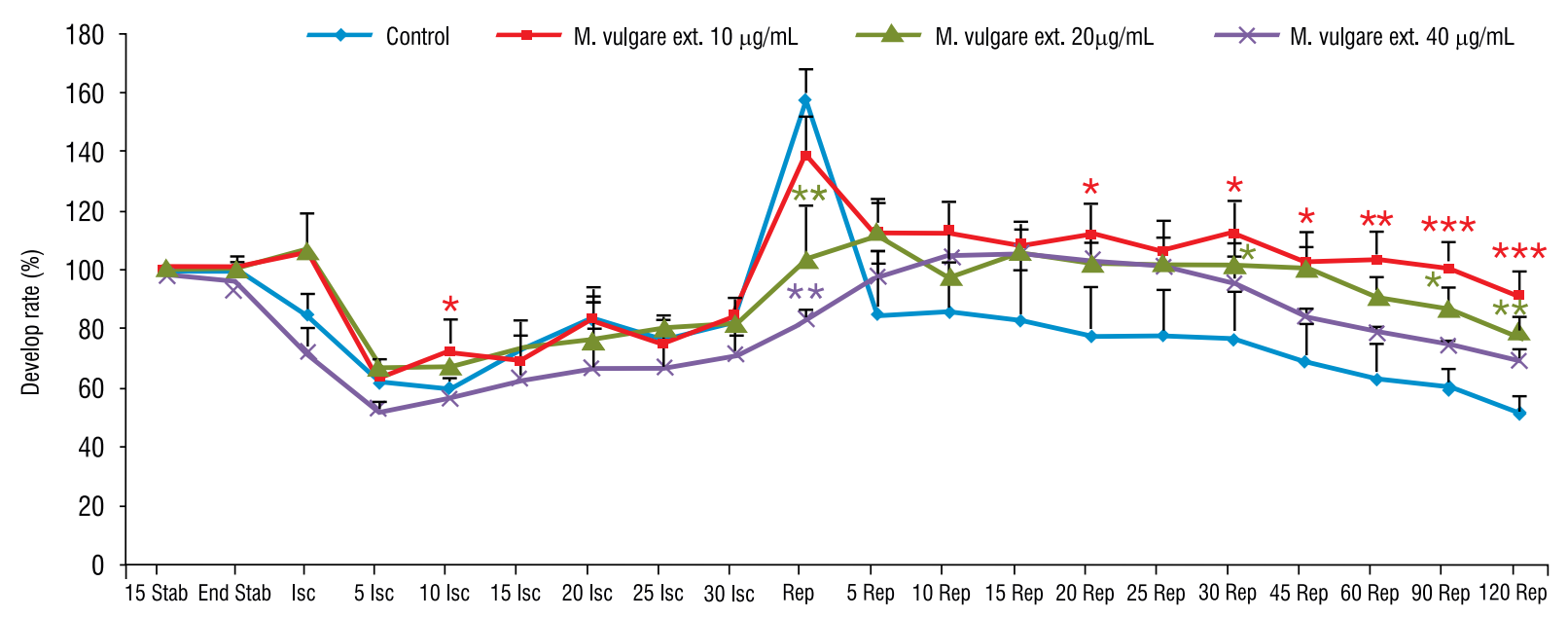

Figure 5. Develop pressure in the control and treated groups receiving 10, 20 and $40 \mu \mathrm{g} / \mathrm{mL}$ of Marrubium vulgare aqueous fraction during whole experiment period. Data are normalised to 15 Stab and represented as mean \pm standard error of the mean (SEM). Stab - stabilisation; Isc — ischaemia; Rep — reperfusion; Ext - extract; $n=6$ rats in each group; ${ }^{*} p<0.05,{ }^{* *} p<0.01,{ }^{* *} p<0.001$.

The considerable changes of $\mathrm{HR}$ in control and treated groups are shown in Figure 4 by $p$ values $\left({ }^{* *} p<0.01,{ }^{*} p<0.05\right)$.

\section{The effect of aqueous extract of $M$. vulgare on develop pressure parameter during $\mathbf{I} / \mathbf{R}$}

Figure 5 is demonstrating the result of DP during the whole period of experiment. By commencing the ischaemic phase, the DP started decreasing from $100 \%$ to $82 \pm 0.08 \%$ during $30 \mathrm{~min}$ of ischaemia in control group. By reperfusion, the DP increased up to $85 \pm 0.17 \%$ and then continuously decreased to
$52 \pm 0.05 \%$ during $120 \mathrm{~min}$ of reperfusion phase. The Figure 5 clearly show that the treated group with $40 \mu \mathrm{g} / \mathrm{mL}$ indicated the lower DP than control group in 30 min of ischaemia. On the contrary, the DP increased much more than control group in 120 min of reperfusion period.

The DP rhythm at doses of $10 \mu \mathrm{g} / \mathrm{mL}$ and $20 \mu \mathrm{g} / \mathrm{mL}$ in ischaemic phase were not regular but after reperfusion the DP of these both treated groups increased much more than control group especially with $10 \mu \mathrm{g} / \mathrm{mL}$ of the extract $(\mathrm{p}<0.001)$. The considerable changes of DP in control and treated groups are 
Table 4. Lactate concentration $(\mathrm{mg} / \mathrm{dL})$ in perfusate at the end of the $30 \mathrm{~min}$ of regional ischaemia and during the first 30 min of reperfusion phase in the control and treated groups receiving 10, 20 and $40 \mu \mathrm{g} / \mathrm{ml}$ of Marrubium vulgare aqueous extract

\begin{tabular}{lcc}
\hline Groups & $\begin{array}{c}\text { Lactate concentration [mg/dL] } \\
\text { At the end of ischaemia }\end{array}$ & $\begin{array}{c}\text { Lactate concentration [mg/dL] } \\
\text { 30 min after reperfusion }\end{array}$ \\
\hline Control + l/R & $2.37 \pm 0.4375$ & $3.0220 \pm 0.28537$ \\
Normal control & $0.7050 \pm 0.15842$ & $0.7050 \pm 0.15842$ \\
M. vulgare extract $(10 \mu \mathrm{g} / \mathrm{mL})$ & $2.18 \pm 0.3414$ & $1.9750 \pm 0.2335^{* *}$ \\
M. vulgare extract $(20 \mu \mathrm{g} / \mathrm{mL})$ & $2.0216 \pm 0.2099$ & $1.6420 \pm 0.20346^{* *}$ \\
M. vulgare extract $(40 \mu \mathrm{g} / \mathrm{mL})$ & $2.4433 \pm 0.3960$ & $2.608 \pm 0.2929$ \\
\hline
\end{tabular}

${ }^{* *} p<0.001$ vs. control group; IR - ischaemia-reperfusion

shown in Figure 5 by $p$ values $\left({ }^{*} p<0.05,{ }^{* *} p<0.01\right.$, $* * * p<0.001)$.

\section{Concentration of lactate in perfusate}

Aqueous extract of $M$. vulgare did not exert considerable positive effect on lactate (a marker of anaerobic metabolism) concentration in perfusate during ischaemia phase (Table 4). According to Table 4 the extract significantly decreased lactate level in perfusate at the dose of $10 \mu \mathrm{g} / \mathrm{mL}$ and $20 \mu \mathrm{g} / \mathrm{mL}$ in the first $30 \mathrm{~min}$ of reperfusion period in comparison to the control $+\mathrm{I} / \mathrm{R}$ group $(* * p<0.01)$.

\section{DISCUSSION}

Since cardiovascular disorders are still one of the leading cause of death all over the world especially in industrial countries, in recent years, using herbal medicines has drawn attention of many researches. The important and definite roles of ROS in the initiate and progress of heart disorders have been reported in several investigations [28]. In ischaemia by cessation of blood flow, the aerobic metabolism stops and the anaerobic metabolism begins. This kind of metabolism makes a decline in intracellular $\mathrm{pH}$ which leads to ionic derangement. By sudden restoration of blood flow to the ischaemic myocardium, the situation becomes worse due to the ROS production in the great amounts. ROS is reactive oxygen species that can directly injure the heart tissue by oxidation of lipids, proteins and DNA, on the other hand they can induce the inflammatory factors $[1,6,26]$.

It has been formerly ascertained that there is a positive and linear relationship between plants phenolic contents and their antioxidant activity, in which higher phenolic content of a plant materials increases the antioxidant activity of the plant. According to our results, the aqueous fraction of $M$. vulgare extract was found to accumulate the phenolic compounds including phenypropanoids (acteoside) and proanthocyanins with a distinguished antioxidant activity. As far as we know, proanthocyanidins (condensed tannins), the water-soluble subclass of the phenolic components, are composed of flavanol (Catechin and epicatechin) units that are rich in fruits like berries $[9,22]$. Catechin and epicatechin, the two most studied compounds from proanthocyanidins, have been reported to have an impressive protective role on cardiovascular system. It is believed that their effectiveness in reducing the risk of myocardial ischaemia, and congestive heart failure have apparently been associated with their antioxidant, anti-inflammatory, and vasodilatory activities $[12,14,16]$. Owing to the fact that condensed tannins scavenge the free hydroxyl and superoxide radicals, they could prevent cardiomyocytes and myocardium against oxidative stress, reduce reperfusion-induced VF and VT, and increase mitochondrial and respiratory chain enzymes (aerobic metabolism induction) as well $[7,11,17,22,29]$. In addition, Jing et al. [13] showed the protective effect of acteoside on lipopolysaccharide-induced inflammation in acute lung injury. They demonstrated that acteoside increased superoxide dismutase (SOD) and inhibited malondialdehyde (MDA) content and levels of proinflammatory cytokines in LPS-stimulated mice. Previously, we reported the cardioprotective effect of methanolic extract of $M$. vulgare in isoproterenolinduced myocardial infarction in rats. In that study it was found that the extract was rich in non-polar secondary metabolites of the plant and marrubiin identified as the main active component [27].

In current study, we evaluated the protective activity of aqueous extract of $M$. vulgare on $\mathrm{I} / \mathrm{R}$ injuries in 
the isolated rat heart along with its antioxidant activity. The phytochemical screening of the aqueous extract showed the presence of acteoside and proanthocyanidins. Based on our findings, the aqueous extract of $M$. vulgare markedly lowered infarct size, and the total VEBs in ischaemia period. Also arrhythmias were decreased in reperfusion phase. These observations point to the protective role of the $M$. vulgare aqueous extract in $\mathrm{l} / \mathrm{R}$ injury. Considering the fact that ROS bursts caused by $\mathrm{I} / \mathrm{R}$ injury result in further destructive reactions and defective cell functions, it seems the protective activity of the $M$. vulgare extract to be partly related to the free radical scavenging activity of the phenolics content of the extract. Moreover, the simultaneous presence of proanthocyanidins and acteoside may be exerts an additive or synergistic effect in protection activity of the extract.

\section{CONCLUSIONS}

Overall, Marrubium vulgare aqueous extract signifying to have medicinally valuable secondary metabolites and exhibited remarkable effects on different cardiac parameters. In general, the present study showed this plant has the potential to be protective against cardiac complications such as I/R injuries. However, further rigorous research is necessary to support the beneficial impact of $M$. vulgare in preventing and/or improving $l / R$ injuries and related risk factors. In addition, assessment of the possible toxicity of the plant extract is requisite to recommend the plant for clinical experiments.

\section{Acknowledgements}

Financial support of this study by the Research Vice-Chancellor of Tabriz University of Medical Sciences is faithfully acknowledged.

\section{REFERENCES}

1. Akhlaghi M, Bandy B. Mechanisms of flavonoid protection against myocardial ischemia-reperfusion injury. J Mol Cell Cardiol. 2009; 46(3): 309-317, doi: 10.1016/j. yjmcc.2008.12.003, indexed in Pubmed: 19133271.

2. Akther N, Shawl AS, Sultana S, et al. Hepatoprotective activity of Marrubium vulgare against paracetamol induced toxicity. J Pharm Res. 2013; 7(7): 565-570, doi: 10.1016/j. jopr.2013.06.023.

3. Bell RM, Mocanu MM, Yellon DM. Retrograde heart perfusion: the Langendorff technique of isolated heart perfusion. J Mol Cell Cardiol. 2011; 50(6): 940-950, doi: 10.1016/j.yjmcc.2011.02.018, indexed in Pubmed: 21385587.

4. Berrougui $H$, Isabelle $M$, Cherki $M$, et al. Marrubium vulgare extract inhibits human-LDL oxidation and enhances HDL-mediated cholesterol efflux in THP-1 macrophage. Life
Sci. 2006; 80(2): 105-112, doi: 10.1016/j.Ifs.2006.08.040, indexed in Pubmed: 17045616.

5. Boudjelal A, Henchiri C, Siracusa L, et al. Compositional analysis and in vivo anti-diabetic activity of wild Algerian Marrubium vulgare L. infusion. Fitoterapia. 2012; 83(2): 286-292, doi: 10.1016/j.fitote.2011.11.005, indexed in Pubmed: 22100836.

6. Dong $L$, Fan $Y$, Shao $X u$, et al. Vitexin protects against myocardial ischemia/reperfusion injury in Langendorffperfused rat hearts by attenuating inflammatory response and apoptosis. Food Chem Toxicol. 2011; 49(12): 3211-3216, doi: 10.1016/j.fct.2011.09.040, indexed in Pubmed: 22001368.

7. Du Yu, Lou H. Catechin and proanthocyanidin B4 from grape seeds prevent doxorubicin-induced toxicity in cardiomyocytes. Eur J Pharmacol. 2008; 591(1-3): 96-101, doi: 10.1016/j. ejphar.2008.06.068, indexed in Pubmed: 18611398.

8. Fofie N, Kiendrebeogo M, Coulibaly K, et al. Mineral salt composition and secondary metabolites of ocimum gratissimum L., an anti-hyperglycemic plant. Nat Prod Chem Res. 2016; 4(5), doi: 10.4172/2329-6836.1000235.

9. Gu L, Kelm MA, Hammerstone JF, et al. Concentrations of proanthocyanidins in common foods and estimations of normal consumption. J Nutr. 2004; 134(3): 613-617, indexed in Pubmed: 14988456.

10. Hamedeyazdan S, Fathiazad F, Sharifi S, et al. Antiproliferative activity of Marrubium persicum extract in the MCF-7 human breast cancer cell line. Asian Pac J Cancer Prev. 2012; 13(11): 5843-5848, indexed in Pubmed: 23317267.

11. Hort MA, Straliotto MR, Duz MS, et al. Cardioprotective effects of a proanthocyanidin-rich fraction from Croton celtidifolius Baill: focus on atherosclerosis. Food Chem Toxicol. 2012; 50(10): 3769-3775, doi: 10.1016/j. fct.2012.07.050, indexed in Pubmed: 22884763.

12. Hotta $Y$, Huang L, Muto $T$, et al. Positive inotropic effect of purified green tea catechin derivative in guinea pig hearts: the measurements of cellular $\mathrm{Ca} 2+$ and nitric oxide release. Eur J Pharmacol. 2006; 552(1-3): 123-130, doi: 10.1016/j.ejphar.2006.09.017, indexed in Pubmed: 17059816.

13. Jing W, Chunhua Ma, Shumin W. Effects of acteoside on lipopolysaccharide-induced inflammation in acute lung injury via regulation of NF- $\kappa$ B pathway in vivo and in vitro. Toxicol Appl Pharmacol. 2015; 285(2): 128-135, doi: 10.1016/j.taap.2015.04.004, indexed in Pubmed: 25902336.

14. Khanna D, Bhardwaj P. Green tea catechins: defensive role in cardiovascular disorders. Chin J Nat Med. 2013; 11(4): 345-353, doi: 10.1016/S1875-5364(13)60051-5, indexed in Pubmed: 23845542.

15. Kim AS, Miller EJ, Wright TM, et al. A small molecule AMPK activator protects the heart against ischemiareperfusion injury. J Mol Cell Cardiol. 2011; 51(1): 24-32, doi: 10.1016/j.yjmcc.2011.03.003, indexed in Pubmed: 21402077.

16. Korish AA, Arafah MM. Catechin combined with vitamins $\mathrm{C}$ and $\mathrm{E}$ ameliorates insulin resistance (IR) and atherosclerotic changes in aged rats with chronic renal failure (CRF). Arch Gerontol Geriatr. 2008; 46(1): 25-39, doi: 10.1016/j. archger.2007.02.006, indexed in Pubmed: 17418908. 
17. Kruger M, Davies N, Myburgh K, et al. Proanthocyanidins, anthocyanins and cardiovascular diseases. Food Res Int. 2014; 59: 41-52, doi: 10.1016/j. foodres.2014.01.046.

18. Nazari A, Sadr SS, Faghihi M, et al. The cardioprotective effect of different doses of vasopressin (AVP) against ischemia-reperfusion injuries in the anesthetized rat heart. Peptides. 2011; 32(12): 2459-2466, doi: 10.1016/j.peptides.2011.10.023, indexed in Pubmed: 22079221.

19. Pukalskas $A$, Venskutonis $P$, Salido $S$, et al. Isolation, identification and activity of natural antioxidants from horehound (Marrubium vulgare L.) cultivated in Lithuania. Food Chem. 2012; 130(3): 695-701, doi: 10.1016/j. foodchem.2011.07.112.

20. Russell RR, Li Ji, Coven DL, et al. AMP-activated protein kinase mediates ischemic glucose uptake and prevents postischemic cardiac dysfunction, apoptosis, and injury. J Clin Invest. 2004; 114(4): 495-503, doi: 10.1172/JCl19297, indexed in Pubmed: 15314686.

21. Sahpaz S, Garbacki N, Tits M, et al. Isolation and pharmacological activity of phenylpropanoid esters from Marrubium vulgare. J Ethnopharmacol. 2002; 79(3): 389-392, doi: 10.1016/S0378-8741(01)00415-9, indexed in Pubmed: 11849848.

22. Schofield P, Mbugua DM, Pell AN. Analysis of condensed tannins: a review. Animal Feed Science and Technology. 2001; 91(1-2): 21-40, doi: 10.1016/s0377-8401(01)00228-0.

23. Sibelius U, Grandel U, Buerke M, et al. Staphylococcal -toxin provokes coronary vasoconstriction and loss in myocardial contractility in perfused rat hearts : role of thromboxane generation. Circulation. 2000; 101(1): 78-85, doi: 10.1161/01.cir.101.1.78.

24. Srinivasan R, Chandrasekar MJN, Nanjan MJ, et al. Antioxidant activity of Caesalpinia digyna root. J Ethnopharmacol. 2007; 113(2): 284-291, doi: 10.1016/j.jep.2007.06.006, indexed in Pubmed: 17686593.

25. Stulzer HK, Tagliari MP, Zampirolo JA, et al. Antioedematogenic effect of marrubiin obtained from Marrubium vulgare. J Ethnopharmacol. 2006; 108(3): 379-384, doi: 10.1016/j.jep.2006.05.023, indexed in Pubmed: 16846706.

26. Wei Bo, Li WW, Ji J, et al. The cardioprotective effect of sodium tanshinone IIA sulfonate and the optimizing of therapeutic time window in myocardial ischemia/reperfusion injury in rats. Atherosclerosis. 2014; 235(2): 318-327, doi: 10.1016/j.atherosclerosis.2014.05.924, indexed in Pubmed: 24911635.

27. Yousefi K, Soraya H, Fathiazad F, et al. Cardioprotective effect of methanolic extract of Marrubium vulgare $L$. on isoproterenol-induced acute myocardial infarction in rats. Indian J Exp Biol. 2013; 51(8): 653-660, indexed in Pubmed: 24228389.

28. Zhao Y, Zhao B. Protective effect of natural antioxidants on heart against ischemia-reperfusion damage. Curr Pharm Biotechnol. 2010; 11(8): 868-874, doi: 10.2174/1389201 10793262105, indexed in Pubmed: 20874692.

29. Zheng J, Lee HC, Bin Sattar MM, et al. Cardioprotective effects of epigallocatechin-3-gallate against doxorubicininduced cardiomyocyte injury. Eur J Pharmacol. 2011; 652(1-3): 82-88, doi: 10.1016/j.ejphar.2010.10.082, indexed in Pubmed: 21114975. 